\title{
The value of time-averaged serum high-sensitivity C-reactive protein in prediction of mortality and dropout in peritoneal dialysis patients
}

This article was published in the following Dove Press journal:

Therapeutics and Clinical Risk Management

16 August 2017

Number of times this article has been viewed

\author{
Shou-Hsuan Liu'-3,* \\ Chao-Yu Chen ${ }^{1, *}$ \\ Yi-Jung $\mathrm{Li}^{1,2}$ \\ $\mathrm{Hsin}-\mathrm{Hsu} \mathrm{Wu}^{1,2}$ \\ Chan-Yu Lin' \\ Yung-Chang Chen' \\ Ming-Yang Chang' \\ Hsiang-Hao Hsu' \\ Cheng-Lung $\mathrm{Ku}^{2,3}$ \\ Ya-Chung Tian'
}

'Kidney Research Center, Department of Nephrology, Lin-Kou Chang Gung Memorial Hospital and Department of Medicine, ${ }^{2}$ Graduate Institute of Clinical Medical Sciences, ${ }^{3}$ Laboratory of Human Immunology and Infectious Diseases, Graduate Institute of Clinical Medical Sciences, Chang Gung University, Taoyuan, Taiwan

*These authors contributed equally to this work
Correspondence: Ya-Chung Tian Department of Nephrology, Chang Gung Memorial Hospital, 199 Tun-Hwa North Road, Taipei 105, Taiwan (R.O.C.)

Tel +8863328 I200 (ext 8I8I)

Fax +8863328 2173

Email dryctian@adm.cgmh.org.tw
Purpose: C-reactive protein (CRP) is a useful biomarker for prediction of long-term outcomes in patients undergoing chronic dialysis. This observational cohort study evaluated whether the time-averaged serum high-sensitivity CRP (HS-CRP) level was a better predictor of clinical outcomes than a single HS-CRP level in patients undergoing peritoneal dialysis (PD).

Patients and methods: We classified 335 patients into three tertiles according to the timeaveraged serum HS-CRP level and followed up regularly from January 2010 to December 2014. Clinical outcomes such as cardiovascular events, infection episodes, newly developed malignancy, encapsulating peritoneal sclerosis (EPS), dropout (death plus conversion to hemodialysis), and mortality were assessed.

Results: During a 5-year follow-up, 164 patients (49.0\%) ceased PD; this included 52 patient deaths (15.5\%), 100 patients $(29.9 \%)$ who converted to hemodialysis, and 12 patients $(3.6 \%)$ who received a kidney transplantation. The Kaplan-Meier survival analysis and log-rank test revealed a significantly worse survival accumulation in patients with high time-average HS-CRP levels. A multivariate Cox regression analysis revealed that a higher time-averaged serum HSCRP level, older age, and the occurrence of cardiovascular events were independent mortality predictors. A higher time-averaged serum HS-CRP level, the occurrence of cardiovascular events, infection episodes, and EPS were important predictors of dropout. The receiver operating characteristic analysis verified that the value of the time-average HS-CRP level in predicting the 5-year mortality and dropout was superior to a single serum baseline HS-CRP level.

Conclusion: This study shows that the time-averaged serum HS-CRP level is a better marker than a single baseline measurement in predicting the 5-year mortality and dropout in PD patients.

Keywords: dropout, encapsulating peritoneal sclerosis, high sensitivity C-reactive protein, malignancy, mortality, peritoneal dialysis

\section{Introduction}

C-reactive protein (CRP), a major acute-phase reactant, is primarily synthesized by the liver, and the serum CRP level rapidly elevates in response to tissue injury and inflammation. ${ }^{1}$ Moreover, the serum CRP level increases in high oxidative status, including vascular atherosclerosis ${ }^{2}$ and malignancies. ${ }^{3,4}$ In addition, some studies reported that CRP itself has pro-inflammatory effect as it can bind to lysosomes of damaged cells and activate the complement system. ${ }^{5,6}$ Serum CRP level is a useful clinical biomarker to predict cardiovascular outcomes ${ }^{7}$ or patient mortality, ${ }^{8}$ as elevated CRP level is well correlated with clinical or subclinical inflammation. ${ }^{9}$

Several studies have described that the uremic milieu is associated with a state of chronic inflammation and high oxidative stress. ${ }^{10-13}$ Dialysis patients have increased 
pro-inflammatory cytokines, including interleukin- 1 beta (IL-1 $\beta$ ), IL-6, and tumor necrosis factor- $\alpha$ (TNF- $\alpha$ ), accompanied by an elevation of serum CRP level. ${ }^{14-19}$ Cardiovascular accidents are the major culprits of death in dialysis patients as both vascular atherosclerosis and calcification are common findings. ${ }^{20}$ Sustained elevation of the serum CRP level has been reported to have a good correlation with cardiovascular deaths in patients on dialysis. ${ }^{21}$

A previous study demonstrated the importance of obtaining a single baseline serum HS-CRP measurement for predicting the 2-year mortality and dropout, including death or transfer to hemodialysis (HD), in patients on PD, independent of age, diabetes, hypoalbuminemia, and the occurrence of cardiovascular events. ${ }^{22}$ The ISPD cardiovascular guideline, therefore, suggests seeking treatable causes in patients on PD with high serum CRP levels. ${ }^{23}$ However, serum CRP levels vary and are increased for only a fraction of time in any given patient on dialysis. ${ }^{24}$ Besides, two prospective studies showed that patients on dialysis with a persistent elevation of CRP had a higher mortality rate than those with occasional CRP elevation. ${ }^{25,26}$ Whether a single baseline serum HS-CRP level can predict longer outcomes remains unclear. Therefore, it was hypothesized that the time-averaged level could be better than a single baseline measurement in representing the long-term inflammatory status and affecting long-term outcome. The aim of this observational cohort study was to explore whether the time-averaged serum HS-CRP level is superior to a single baseline measurement for predicting 5-year mortality and dropout in patients on PD.

\section{Patients and methods \\ Study population and follow-up}

This observational cohort study conformed with the guidelines of the Declaration of Helsinki. Ethics approval (approval number 201600804B0) was obtained from the Institutional Review Board of Chang Gung Medical foundation in Taiwan. Because this study involved a retrospective review of existing data, approval from the Institutional Review Board was obtained without specific informed consent from the patients. Moreover, all individual information was safely protected by delinking identifying information from the main data set and only this delinked information was available to the investigators. Furthermore, all data were anonymously processed. The Institutional Review Board had waived the requirement to obtain any informed consent. Finally, all primary data were collected in accordance with the Strengthening the Reporting of Observational Studies in Epidemiology (STROBE) guidelines.
In total, 335 patients receiving PD for more than 3 months and having regular HS-CRP examination at 12-month intervals were recruited to this study. All patients were followed up for 60 months and the clinical parameters and outcomes were recorded regularly. The patients were stratified into three tertiles according to their time-averaged serum HS-CRP levels. Patients were excluded if they had acute events (active infection, acute cardiovascular diseases, or cerebrovascular disease) occurring within 1 month before and after each HS-CRP measurement, less than two separate measurements of HS-CRP during the entire follow-up period, a diagnosis of malignancy or encapsulating peritoneal sclerosis (EPS) before January 2010, or loss to follow-up.

Baseline demographic and clinical data, such as gender, age, body mass index (BMI), the presence of comorbidities such as diabetes mellitus (DM), coronary artery disease (CAD), congestive heart failure (CHF), stroke, systemic lupus erythematosus (SLE), liver cirrhosis, hepatitis B, and hepatitis $\mathrm{C}$, the duration of PD at study entry, the PD system used (Fresenius Stay Safe or Baxter), the PD modality (automated PD or continuous ambulatory PD), daily dwell volume, the use of icodextrin, the use of nutrineal, the mean dialysate dextrose level, the dialysate calcium level (2.5 or $3.5 \mathrm{mEq} / \mathrm{L}$ ), residual urine, hemogram, and biochemical parameters were obtained. PD membrane characteristics such as dialysate-to-plasma concentrations for creatinine $\left(\mathrm{D} / \mathrm{P}_{\mathrm{Cr}}\right)$, results of the peritoneal equilibrium test (PET), total weekly $\mathrm{Kt} / \mathrm{V}$ urea, and total weekly creatinine clearance $(\mathrm{CCr})$ were assessed. During the 60-month follow-up, clinical outcomes such as cardiovascular event(s), infection episode(s), newly developed malignancy, encapsulating peritoneal sclerosis (EPS), dropout (death plus conversion to HD), and mortality were recorded. Residual urine was defined as a daily total urine volume of $>100 \mathrm{~mL} .{ }^{27}$ Cardiovascular events were defined as at least one acute myocardial infarction or cerebral vascular accident during the entire follow-up period. Infection episodes were defined as at least one PDor non-PD-related infection during the entire follow-up period. Malignancy was defined as newly diagnosed cancer confirmed by pathologic report during the entire follow-up period. The diagnosis of EPS was based on the clinical bowel obstructive symptoms with compatible abdominal computed tomographic findings.

\section{Laboratory parameters}

Blood samples were collected within the next few days of the clinical evaluation during a stable PD routine assessment to minimize the effects resulting from any acute 
event. Serum HS-CRP levels were analyzed by an immunonephelometric method (Nanopia CRP; Daiichi, Tokyo, Japan) and measured annually between 2010 and 2014. The baseline HS-CRP was defined as the October 2009 value. The time-averaged HS-CRP was defined as the mean of all the HS-CRP values obtained annually. Each patient had at least two separate measurements of HS-CRP. The lower limit of detection is $<0.15 \mathrm{mg} / \mathrm{L}$, and the reference value is $<5 \mathrm{mg} / \mathrm{L}$. Serum intact parathyroid hormone (iPTH) levels were measured by a chemiluminometric immunoassay (ADVIA Centaur iPTH; Siemens Medical Solutions Diagnostics, New York, NY, USA). The reference range for iPTH is $7-53 \mathrm{pg} / \mathrm{mL}$. All other biochemical parameters were analyzed by standard laboratory procedures using an automated analyzer.

\section{PD membrane characteristics}

The adequacy of PD was assessed by measuring the total weekly Kt/V urea and CCr. The total weekly $\mathrm{CCr}$ was normalized to $1.73 \mathrm{~m}^{2}$ body surface area (BSA). Dialysate creatinine level was corrected for glucose interference. Dialysate-to-plasma concentrations for creatinine $\left(\mathrm{D} / \mathrm{P}_{\mathrm{Cr}}\right)$ at the end of a 4-hour dwell was calculated. All patients were classified into one of four transport categories (high, high average, low average, and low) based on results of the PET. ${ }^{28}$

\section{Statistical analysis}

Continuous variables are expressed as the means \pm standard deviations, and categorical variables are expressed as numbers and percentages (shown in brackets). All data were checked for normal distribution and equal variances before they were analyzed. For comparisons among three patient groups, continuous variables were analyzed by one-way analysis of variance (ANOVA), whereas categorical variables were analyzed by chi-square or Fisher's exact test. $P$-values less than $0.05(P<0.05)$ were considered statistically significant. Predictors of mortality were examined using Kaplan-Meier analysis. The log-rank test was used to compare survival curves among three patient groups. Univariate Cox regression analysis was used initially to compare the frequencies of possible risk factors for mortality. The multicollinearity of the variables was checked by variance inflation factor (VIF) before running the multivariate analysis. Any variable with a VIF more than 5 would be eliminated from the model. To control for potential confounding factors, multivariate Cox regression analysis (enter method) was performed to analyze the factors identified as significant $(P<0.05)$ in univariate analysis that met the proportional hazards assumption.
To compare the mortality and dropout predictability of serum baseline and time-averaged HS-CRP level, receiver operating characteristic (ROC) curve analysis was constructed. The differences of the areas under ROC curves (AUC) were examined and compared by using roccomp command in STATA. All analyses were performed using PASW Statistics for Windows, Version 18.0 (SPSS Inc.; Chicago, IL, USA) and STATA for Windows, Version 14.0 (STATA Corp., TX, USA).

\section{Results \\ Baseline patient demographic and biochemical characteristics}

We enrolled 335 patients (mean age $48.7 \pm 13.5$ years; range 14-89 years) in this cohort observational study. Five patients (1.5\%) were younger than 18 years. The mean baseline PD duration when patients were enrolled was $52.7 \pm 41.3$ months (range 3-222 months). Further analysis of PD duration in these patients revealed 200 patients $(59.7 \%)$ with PD duration of $1-5$ years, 107 patients $(31.9 \%)$ with $\mathrm{PD}$ duration of 5-10 years, and 17 patients (5.1\%) with PD duration of more than 10 years. All of the patients received regular HSCRP measurement at an interval of 12 months. The overall average number of HS-CRP measurement was 4.58 times per patient. Table 1 shows the baseline demographic and laboratory characteristics of these 335 patients categorized into three tertiles based on the time-averaged serum HS-CRP level. The mean time-averaged serum HS-CRP values were $1.38(0.25-2.65) \mathrm{mg} / \mathrm{L}$ in the lower tertile (T1), $5.07(2.66-8.55) \mathrm{mg} / \mathrm{L}$ in the middle tertile (T2), 21.05 (8.58-109.47) $\mathrm{mg} / \mathrm{L}$ in the upper tertile (T3), and $9.18 \mathrm{mg} / \mathrm{L}$ overall for the study population. Among the three tertiles, no significant differences were observed for gender, comorbidities including CHF, stroke, SLE, liver cirrhosis, and hepatitis C, the PD system (Fresenius Stay Safe or Baxter), the PD modality (automated PD or continuous ambulatory PD), the use of icodextrin, the use of nutrineal, and the dialysate calcium level $(2.5$ or $3.5 \mathrm{mEq} / \mathrm{L})$. The mean age $(P=0.001)$ differed significantly across the three tertiles that is, 46.4 years in T1, 47.0 years in T2, and 52.6 years in T3. The number of patients with DM $(P=0.001)$, CAD $(P=0.042)$, and hepatitis $\mathrm{B}(P=0.025)$ also differed significantly. Significant increases in the PD duration $(P=0.022)$ and BMI values $(P<0.001)$ were observed across the three tertiles with the highest tertile having the highest values. Up to $80.2 \%$ of patients in $\mathrm{T} 1$ had residual urine $(P<0.001)$, whereas $68.5 \%$ of patients in T2 and $52.3 \%$ of patients in T3 had residual urine. Both daily dwell volume $(P=0.020)$ and 
Table I Baseline demographic and laboratory characteristics of patients on PD categorized according to time-averaged serum HS-CRP levels

\begin{tabular}{|c|c|c|c|c|c|}
\hline $\begin{array}{l}\text { Time-averaged serum } \\
\text { HS-CRP (mg/L) }\end{array}$ & $\begin{array}{l}\begin{array}{l}\text { Total } \\
(n=335)\end{array} \\
9.18 \pm \mid 2.28 \\
(0.25-109.47)\end{array}$ & $\begin{array}{l}\text { Lower tertile } \\
(n=112) \\
1.38 \pm 0.67 \\
(0.25-2.65)\end{array}$ & $\begin{array}{l}\text { Middle tertile } \\
(\mathrm{n}=\mathrm{III}) \\
5.07 \pm I .69 \\
(2.66-8.55)\end{array}$ & $\begin{array}{l}\text { Upper tertile } \\
(n=I 12) \\
21.05 \pm 15.16 \\
(8.58-109.47)\end{array}$ & $P$-value \\
\hline Male & II5 (34.3) & $37(33.0)$ & $41(36.9)$ & $37(33.0)$ & 0.778 \\
\hline Age (years) & $48.7 \pm 13.5$ & $46.4 \pm 13.7$ & $47.0 \pm 12.6$ & $52.6 \pm 13.5$ & 0.001 \\
\hline Body mass index $\left(\mathrm{kg} / \mathrm{m}^{2}\right)$ & $22.5 \pm 3.6$ & $21.5 \pm 3.1$ & $22.6 \pm 3.2$ & $23.4 \pm 4.1$ & $<0.001$ \\
\hline DM & $54(16.1)$ & $10(8.9)$ & $14(12.6)$ & $30(26.8)$ & 0.001 \\
\hline CAD & $10(3.0)$ & I $(0.9)$ & $2(1.8)$ & $7(6.3)$ & 0.042 \\
\hline $\mathrm{CHF}$ & $21(6.3)$ & $7(6.3)$ & $9(8.1)$ & $5(4.5)$ & 0.533 \\
\hline Stroke & $18(5.4)$ & $2(1.8)$ & $7(6.3)$ & $9(8.0)$ & 0.101 \\
\hline SLE & $13(3.9)$ & $3(2.7)$ & $6(5.4)$ & $4(3.6)$ & 0.561 \\
\hline Liver cirrhosis & $18(5.4)$ & $4(3.6)$ & $4(3.6)$ & $10(8.9)$ & 0.123 \\
\hline Hepatitis B & $43(12.8)$ & $9(8.0)$ & $12(10.8)$ & $22(19.6)$ & 0.025 \\
\hline Hepatitis C & $21(6.3)$ & II (9.8) & $5(4.5)$ & $5(4.5)$ & 0.164 \\
\hline PD duration (months) & $52.7 \pm 41.3$ & $46.3 \pm 40.1$ & $50.6 \pm 38.8$ & $61.1 \pm 43.9$ & 0.022 \\
\hline PD system (Fresenius) & $7(2.1)$ & I (0.9) & $2(1.8)$ & $4(3.6)$ & 0.362 \\
\hline PD modality (APD) & $64(19.1)$ & $19(17.0)$ & $24(21.6)$ & $21(18.8)$ & 0.672 \\
\hline Daily dwell volume $(L)$ & $8.89 \pm 1.96$ & $8.49 \pm 1.94$ & $9.20 \pm 2.03$ & $8.99 \pm 1.86$ & 0.020 \\
\hline Icodextrin use & $176(52.5)$ & $54(48.2)$ & $60(54.1)$ & $62(55.4)$ & 0.522 \\
\hline Nutrineal use & $13(3.9)$ & $3(2.7)$ & $4(3.6)$ & $6(5.4)$ & 0.574 \\
\hline Dialysate dextrose (\%) & $1.86 \pm 0.48$ & $1.72 \pm 0.44$ & $1.90 \pm 0.47$ & $1.96 \pm 0.50$ & 0.001 \\
\hline Dialysate calcium (2.5 mEq/L) & $139(4 \mid .5)$ & $46(4 I .1)$ & $44(39.6)$ & $49(43.8)$ & 0.614 \\
\hline Residual urine & $223(67.0)$ & $89(80.2)$ & $76(68.5)$ & $58(52.3)$ & $<0.001$ \\
\hline White blood cell count $(I, 000 / \mu \mathrm{L})$ & $7.553 \pm 2.649$ & $6.685 \pm 2.354$ & $7.619 \pm 2.190$ & $8.688 \pm 2.832$ & $<0.001$ \\
\hline Hemoglobin (g/dL) & $10.18 \pm 1.53$ & $10.37 \pm 1.60$ & $10.33 \pm 1.34$ & $9.85 \pm 1.60$ & 0.017 \\
\hline Platelet count $(\mathrm{I}, 000 / \mu \mathrm{L})$ & $249.27 \pm 78.29$ & $225.60 \pm 62.67$ & $259.50 \pm 82.69$ & $262.80 \pm 82.96$ & $<0.001$ \\
\hline Albumin (g/dL) & $4.0 \mathrm{I} \pm 0.42$ & $4.05 \pm 0.40$ & $4.03 \pm 0.42$ & $3.94 \pm 0.44$ & 0.117 \\
\hline Total cholesterol (mg/dL) & $204.2 \pm 50.3$ & $203.3 \pm 47.1$ & $205.0 \pm 50.7$ & $204.4 \pm 53.3$ & 0.966 \\
\hline $\mathrm{HDL}(\mathrm{mg} / \mathrm{dL})$ & $47.2 \pm 14.9$ & $54.0 \pm 15.1$ & $44.5 \pm 13.8$ & $42.9 \pm 13.5$ & $<0.001$ \\
\hline LDL (mg/dL) & $120.1 \pm 40.9$ & $120.2 \pm 40.5$ & $120.2 \pm 43.4$ & $120.0 \pm 39.3$ & 0.999 \\
\hline Triglycerides (mg/dL) & $183.2 \pm 106.1$ & $146.5 \pm 79.2$ & $204.5 \pm 119.7$ & $197.8 \pm 106.3$ & $<0.001$ \\
\hline $\mathrm{HbAlc}(\%)$ & $5.6 \mathrm{I} \pm 0.92$ & $5.43 \pm 0.91$ & $5.59 \pm 0.88$ & $5.80 \pm 0.95$ & 0.011 \\
\hline Blood urea nitrogen $(\mathrm{mg} / \mathrm{dL})$ & $58.84 \pm 17.97$ & $61.24 \pm 17.48$ & $56.32 \pm 19.05$ & $58.93 \pm 17.14$ & 0.123 \\
\hline Creatinine (mg/dL) & $11.27 \pm 2.96$ & $11.32 \pm 3.03$ & $11.49 \pm 3.19$ & $10.99 \pm 2.63$ & 0.432 \\
\hline Uric acid (mg/dL) & $6.83 \pm 1.27$ & $6.68 \pm 1.14$ & $6.79 \pm 1.30$ & $7.04 \pm 1.35$ & 0.096 \\
\hline Calcium (mg/dL) & $9.99 \pm 1.03$ & $9.79 \pm 1.09$ & $10.05 \pm 1.12$ & $10.14 \pm 0.84$ & 0.027 \\
\hline Phosphorus (mg/dL) & $4.99 \pm 1.32$ & $4.94 \pm 1.18$ & $4.99 \pm 1.27$ & $5.03 \pm 1.5 \mid$ & 0.883 \\
\hline Aluminum $(\mu g / d L)$ & $0.90 \pm 0.89$ & $0.79 \pm 0.75$ & $0.79 \pm 0.79$ & $1.11 \pm 1.08$ & 0.015 \\
\hline iPTH (pg/mL) & $336.5 \pm 383.8$ & $299.6 \pm 345.0$ & $347.1 \pm 376.6$ & $362.9 \pm 426.1$ & 0.439 \\
\hline Transferrin saturation (\%) & $27.2 \pm 12.4$ & $28.8 \pm 12.0$ & $27.6 \pm 10.7$ & $25.4 \pm \mid 4.1$ & 0.115 \\
\hline Ferritin $(\mu g / L)$ & $326.0 \pm 531.6$ & $225.8 \pm 349.0$ & $304.3 \pm 432.4$ & $446.4 \pm 720.0$ & 0.010 \\
\hline
\end{tabular}

Note: Continuous variables are given as mean \pm standard deviation, and categorical variables, as number (percentage).

Abbreviations: HS-CRP, high-sensitivity C-reactive protein; DM, diabetes mellitus; CAD, coronary artery disease; CHF, congestive heart failure; SLE, systemic lupus erythematosus; APD, automated peritoneal dialysis; HDL, high-density lipoprotein; LDL, low-density lipoprotein; HbAIc, glycated hemoglobin; iPTH, intact parathyroid hormone.

mean dialysate dextrose level $(P=0.001)$ were significantly different. The white blood cell count $(P<0.001)$ and the platelet count $(P<0.001)$ were significantly increased as the tertile increased, whereas the hemoglobin level $(P=0.017)$ decreased with increasing tertile.

The lipid profile showed a significant increase in triglyceride levels $(P<0.001)$ and a decrease in high-density lipoprotein (HDL) levels $(P<0.001)$ as the tertile increased, whereas low-density lipoprotein (LDL) and total cholesterol levels did not differ across the three tertiles. Glycated hemoglobin $(\mathrm{HbA1c})$ levels $(P=0.011)$ were measured in all of the patients, and the results revealed a significant increase as the tertile increased. The serum calcium $(P=0.027)$, aluminum $(P=0.015)$, and ferritin levels $(P=0.010)$ were highest in T3 compared with the other tertiles. The differences in blood urea nitrogen, serum creatinine, albumin, 
Table 2 Peritoneal membrane characteristics of patients on PD categorized according to time-averaged serum HS-CRP levels

\begin{tabular}{|c|c|c|c|c|c|}
\hline $\begin{array}{l}\text { Time-averaged serum } \\
\text { HS-CRP }(\mathrm{mg} / \mathrm{L})\end{array}$ & $\begin{array}{l}\begin{array}{l}\text { Total } \\
(\mathrm{n}=335)\end{array} \\
9.18 \pm 12.28 \\
(0.25-109.47)\end{array}$ & $\begin{array}{l}\text { Lower tertile } \\
(n=1 \mid 2) \\
1.38 \pm 0.67 \\
(0.25-2.65)\end{array}$ & $\begin{array}{l}\text { Middle tertile } \\
(n=I I I) \\
5.07 \pm I .69 \\
(2.66-8.55)\end{array}$ & $\begin{array}{l}\text { Upper tertile } \\
(n=I I 2) \\
21.05 \pm 15.16 \\
(8.58-109.47)\end{array}$ & $P$-value \\
\hline Dialysate/plasma creatinine & $0.63 \pm 0.12$ & $0.62 \pm 0.11$ & $0.64 \pm 0.12$ & $0.64 \pm 0.12$ & 0.149 \\
\hline Peritoneal equilibration test & & & & & 0.087 \\
\hline High & $19(5.7)$ & $2(1.8)$ & $8(7.2)$ & $9(8.1)$ & 0.091 \\
\hline High average & $117(35.1)$ & 37 (33.3) & $45(40.5)$ & $35(31.5)$ & 0.331 \\
\hline Low average & $154(46.2)$ & $52(46.8)$ & $45(40.5)$ & $57(5 \mathrm{I} .4)$ & 0.268 \\
\hline Low & $43(12.9)$ & $20(\mid 8.0)$ & $13(11.7)$ & $10(9.0)$ & 0.121 \\
\hline Weekly Kt/V urea (total) & $2.19 \pm 0.38$ & $2.21 \pm 0.38$ & $2.19 \pm 0.38$ & $2.16 \pm 0.39$ & 0.587 \\
\hline Weekly CCr (normalized) & $61.1 \pm 15.0$ & $62.3 \pm 17.2$ & $61.2 \pm 15.2$ & $59.7 \pm 12.0$ & 0.422 \\
\hline
\end{tabular}

Note: Continuous variables are given as mean \pm standard deviation, and categorical variables, as number (percentage).

Abbreviations: HS-CRP, high-sensitivity C-reactive protein; $\mathrm{CCr}$, creatinine clearance; PD, peritoneal dialysis.

uric acid, phosphorus, and iPTH levels did not reach statistical significance.

\section{Baseline peritoneal membrane characteristics}

The peritoneal membrane characteristics in patients on PD are shown in Table 2. Among the three tertiles, the value of $\mathrm{D} / \mathrm{P}_{\mathrm{Cr}}$ and the peritoneal transport status did not differ significantly. However, a trend of more high transporters in the upper tertile and more low transporters in the lower tertile was suggested. For example, $8.1 \%$ of the T3 patients were high transporters and $9.0 \%$ of the $\mathrm{T} 3$ patients were low transporters, whereas $1.8 \%$ of the $\mathrm{T} 1$ patients were high transporters and $18.0 \%$ of the $\mathrm{T} 1$ patients were low transporters. During follow-up, 13 of 19 patients with high transporters ceased PD, including seven patient deaths and six patients converting to HD. Moreover, 16 of 43 patients with low transporters ceased PD during follow-up, including six patient deaths, nine patients converting to HD, and one patient receiving kidney transplantation. No significant differences were observed in the weekly $\mathrm{Kt} / \mathrm{V}$ urea (total) and $\mathrm{CCr}$ (normalized) values among the three tertiles.

\section{Patient survival, technique survival, cardiovascular events, infection episodes, newly developed malignancy, and encapsulating peritoneal sclerosis during the 60-month follow-up}

During the 60-month follow-up, 164 patients (49.0\%) ceased PD, including 52 patients who died (15.5\%), 100 patients $(29.9 \%)$ who converted to HD, and 12 patients (3.6\%) who underwent kidney transplantation (Table 3). Significant differences were observed for mortality $(P<0.001)$, transplantation rate $(P=0.043)$, and technique survival $(P=0.002)$ among the three tertiles, whereas no significant difference was evident in the number of patients converting to HD among the three groups (Table 3 ). The causes of death were infection $(9.3 \%)$, followed by cardiovascular event (3.0\%), sudden death (1.8\%), and malignancy $(1.5 \%)$. The leading cause of conversion to HD was PD peritonitis (18.8\%).

The Kaplan-Meier survival analysis and log-rank test revealed that the cumulative patient survival rate was significantly different between T3 and T1 $(P<0.001)$, T3 and T2 $(P=0.006)$, and T2 and T1 ( $P=0.033$; Figure 1$)$. In addition, these analyses demonstrated that the cumulative technique survival rate in T1 was significantly higher than that in T3 $(P<0.001$; Figure 2). However, despite a trend toward a higher cumulative technique survival rate in the lower HSCRP tertiles, the difference did not reach significance for the comparisons between T3 and T2 $(P=0.096)$ and T2 and T1 $(P=0.058)$.

During the 60-month follow-up, significant differences were observed in PD-related and non-PD-related infection episodes $(P=0.019)$ among the three tertiles. Because the serum CRP has been recognized as a cardiovascular risk factor, the predictive value of time-averaged serum HS-CRP for subsequent cardiovascular events during a follow-up period of 60 months were examined. More patients (37.5\%) in $\mathrm{T} 3 \mathrm{had}$ suffered from cardiovascular events during this period than patients in T2 $(26.1 \%)$ and T1 $(17.9 \% ; P=0.004)$. During the entire follow-up period, 35 patients $(10.4 \%)$ developed malignancies and 16 patients (4.8\%) sustained EPS. The incidence of malignancy in the three tertiles was not significantly different, with malignancy occurring in 9 patients $(8.0 \%)$ in $\mathrm{T} 1,8$ patients $(7.2 \%)$ in $\mathrm{T} 2$, and 18 patients $(16.1 \%)$ in T3. Although a trend toward a higher incidence of EPS in the upper tertile was suggested, statistical significance was not reached. These results imply that patients in the higher HS-CRP tertiles are at a higher risk 
Table 3 Clinical outcomes in the PD patients categorized according to time-averaged serum HS-CRP levels

\begin{tabular}{|c|c|c|c|c|c|}
\hline $\begin{array}{l}\text { Time-averaged serum } \\
\text { HS-CRP (mg/L) }\end{array}$ & $\begin{array}{l}\begin{array}{l}\text { Total } \\
(n=335)\end{array} \\
9.18 \pm \mid 2.28 \\
(0.25-109.47)\end{array}$ & $\begin{array}{l}\text { Lower tertile } \\
(n=I I 2) \\
1.38 \pm 0.67 \\
(0.25-2.65)\end{array}$ & $\begin{array}{l}\text { Middle tertile } \\
(n=I I I) \\
5.07 \pm I .69 \\
(2.66-8.55)\end{array}$ & $\begin{array}{l}\text { Upper tertile } \\
(n=112) \\
21.05 \pm 15.16 \\
(8.58-109.47)\end{array}$ & $P$-value \\
\hline Outcomes & & & & & $<0.001$ \\
\hline Death & $52(15.5)$ & $6(5.4)$ & $15(13.5)$ & $31(27.7)$ & $<0.001$ \\
\hline Infection & $31(9.3)$ & $3(2.7)$ & $9(8.1)$ & $19(17.0)$ & 0.001 \\
\hline Cardiovascular event & $10(3.0)$ & I (0.9) & $4(3.6)$ & $5(4.5)$ & 0.261 \\
\hline Malignancy & $5(1.5)$ & $0(0)$ & I (0.9) & $4(3.6)$ & 0.072 \\
\hline Sudden death & $6(1.8)$ & $2(1.8)$ & $\mathrm{I}(0.9)$ & $3(2.7)$ & 0.606 \\
\hline Transfer to HD & $100(29.9)$ & $32(28.6)$ & $35(31.5)$ & $33(29.5)$ & 0.885 \\
\hline PD peritonitis & $63(18.8)$ & $19(17.0)$ & $23(20.7)$ & $21(18.8)$ & 0.773 \\
\hline Membrane failure & $8(2.4)$ & $3(2.7)$ & $5(4.5)$ & $0(0)$ & 0.086 \\
\hline EPS & $16(4.8)$ & $4(3.6)$ & $5(4.5)$ & $7(6.3)$ & 0.634 \\
\hline Abdominal operation & $7(2.1)^{\prime}$ & $4(3.6)$ & $2(1.8)$ & I (0.9) & 0.362 \\
\hline Mechanical complication & $2(0.6)$ & I (0.9) & $0(0)$ & I (0.9) & 0.607 \\
\hline ADL disability & $4(1.2)$ & I (0.9) & $0(0)$ & $3(2.7)$ & 0.172 \\
\hline Transplantation & $12(3.6)$ & $2(1.8)$ & $8(7.2)$ & $2(1.8)$ & 0.043 \\
\hline Technique survival & $|7|(5 \mid .0)$ & $72(64.3)$ & $53(47.7)$ & $46(4 I . I)$ & 0.002 \\
\hline Cardiovascular event(s) & $91(27.2)$ & $20(17.9)$ & $29(26.1)$ & $42(37.5)$ & 0.004 \\
\hline Infection episode(s) & $221(66.0)$ & $64(57.1)$ & $73(65.8)$ & $84(75.0)$ & 0.019 \\
\hline Malignancy & $35(10.4)$ & $9(8.0)$ & $8(7.2)$ & $18(16.1)$ & 0.057 \\
\hline Urothelial cell carcinoma & $11(3.3)$ & $3(2.7)$ & $4(3.6)$ & $4(3.6)$ & 0.908 \\
\hline Renal cell carcinoma & $7(2.1)$ & $2(1.8)$ & $3(2.7)$ & $2(1.8)$ & 0.859 \\
\hline Breast cancer & $4(1.2)$ & I (0.9) & $0(0)$ & $3(2.7)$ & 0.172 \\
\hline Thyroid cancer & $4(1.2)$ & $\mathrm{I}(0.9)$ & I (0.9) & $2(1.8)$ & 0.779 \\
\hline Hepatocellular carcinoma & $2(0.6)$ & $0(0)$ & $0(0)$ & $2(1.8)$ & 0.135 \\
\hline Gynecologic cancer & $2(0.6)$ & I (0.9) & $0(0)$ & I (0.9) & 0.607 \\
\hline Prostate cancer & $\mathrm{I}(0.3)$ & I (0.9) & $0(0)$ & $0(0)$ & 0.368 \\
\hline Lung cancer & $\mathrm{I}(0.3)$ & $0(0)$ & $0(0)$ & $\mathrm{I}(0.9)$ & 0.368 \\
\hline Rectal cancer & $2(0.6)$ & $0(0)$ & $0(0)$ & $2(1.8)$ & 0.135 \\
\hline Brain giloma & $\mathrm{I}(0.3)$ & $0(0)$ & $0(0)$ & I (0.9) & 0.368 \\
\hline EPS & $16(4.8)$ & $4(3.6)$ & $5(4.5)$ & $7(6.3)$ & 0.634 \\
\hline
\end{tabular}

Note: Categorical variables are given as number (percentage).

Abbreviations: PD, peritoneal dialysis; HS-CRP, high-sensitivity C-reactive protein; HD, hemodialysis; ADL, activities of daily living; EPS, encapsulating peritoneal sclerosis.

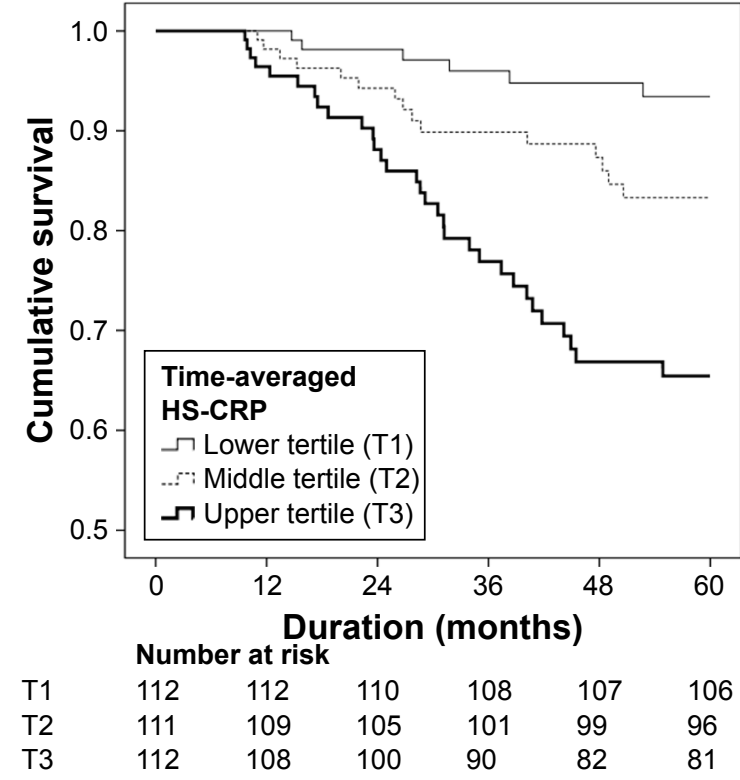

Figure I Comparison of the cumulative patient survival during the 5-year follow-up. The 5-year patient survival was assessed using a Kaplan-Meier analysis, and the significance of differences was determined by the log-rank test. Results of the Kaplan-Meier survival analysis are shown. Patients with high HS-CRP levels had higher mortality rates than patients in the low HS-CRP groups (log-rank test, $\chi^{2}=24.400, P<0.001$ )

Abbreviation: HS-CRP, high-sensitivity C-reactive protein. of developing infection(s) and cardiovascular event(s) over a 60-month period.

\section{Time-averaged serum HS-CRP is an independent predictor of mortality and dropout}

To further evaluate the independent predictors of mortality, a Cox regression analysis was performed. The univariate Cox regression analysis demonstrated that higher baseline $(P=0.001)$ and time-averaged $(P<0.001)$ serum HS-CRP levels, older age $(P<0.001)$, underlying DM $(P<0.001)$, underlying $\mathrm{CAD}(P=0.005)$, underlying stroke $(P=0.005)$, absence of residual urine $(P=0.031)$, lower serum albumin levels $(P=0.001)$, higher HbA1c levels $(P<0.001)$, lower serum creatinine levels $(P=0.048)$, lower serum transferrin saturation levels $(P=0.020)$, higher dialysate-to-plasma concentrations for creatinine $(P=0.025)$, and the occurrence of cardiovascular event(s) $(P<0.001)$ or infective episode(s) ( $P=0.025$ ) during the 60-month follow-up were significant risk factors for mortality (Table 4). Factors identified as 


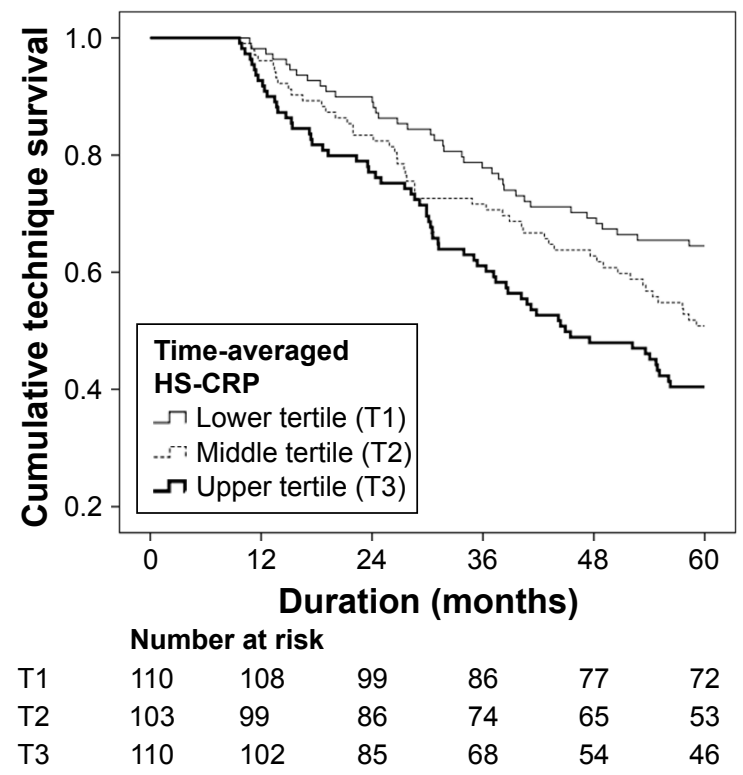

Figure 2 Comparison of the cumulative technique survival (transplantation censored) during the 5-year follow-up. The 5-year technique survival was assessed using a Kaplan-Meier analysis and the differences were assessed for significance by the log-rank test. Results of the Kaplan-Meier technique survival analysis are shown. Patients with high HS-CRP levels had higher death or dropout rates than patients in the lower HS-CRP groups (log-rank test, $\chi^{2}=12.822, P=0.002$ ).

Abbreviation: $\mathrm{HS}-\mathrm{CRP}$, high-sensitivity $\mathrm{C}$-reactive protein. significant $(P<0.05)$ in the univariate analysis were included in the multivariable Cox regression mode (enter method). The multicollinearity of these variables was checked, and there was no variable with a VIF more than 5. Only higher time-averaged serum HS-CRP levels $(P=0.044)$, older age $(P<0.001)$, and the occurrence of cardiovascular event(s) $(P=0.027)$ during the entire follow-up period were recognized as independent predictors of mortality (Table 4). Every $1-\mathrm{mg} / \mathrm{L}$ increase in the time-averaged serum HSCRP level was accompanied by an increase in mortality of $2.8 \%$ independently. To compare mortality predictability of serum baseline and time-averaged HS-CRP levels, ROC curve analyses were conducted. As shown in Figure 3, the mortality predictability of serum time-averaged HS-CRP levels appeared superior to serum baseline HS-CRP levels (AUCs: 0.717 compared with $0.653 ; P=0.028$ ).

Univariate and multivariate Cox regression analyses were also performed to recognize the risk factors for dropout. The univariate Cox regression analysis revealed that higher baseline $(P=0.048)$ and time-averaged $(P<0.001)$ serum HSCRP levels, older age $(P<0.001)$, underlying DM $(P=0.001)$

Table 4 Hazard ratio of mortality in univariate and multivariate Cox regression analysis

\begin{tabular}{|c|c|c|c|c|c|c|}
\hline & \multicolumn{3}{|c|}{ Univariate } & \multicolumn{3}{|c|}{ Multivariate (enter method) } \\
\hline & HR & $95 \% \mathrm{Cl}$ & $P$-value & HR & $95 \% \mathrm{Cl}$ & $P$-value \\
\hline Baseline serum HS-CRP (mg/L) & 1.018 & $1.007-1.028$ & 0.001 & 0.984 & $0.961-1.008$ & 0.187 \\
\hline Time-averaged serum HS-CRP (mg/L) & 1.037 & $1.025-1.050$ & $<0.001$ & 1.028 & $1.001-1.056$ & 0.044 \\
\hline Male & 1.005 & $0.563-1.795$ & 0.986 & & & \\
\hline Age (years) & 1.083 & I.059-I.108 & $<0.001$ & 1.066 & $1.036-1.096$ & $<0.001$ \\
\hline Body mass index $\left(\mathrm{kg} / \mathrm{m}^{2}\right)$ & 1.058 & $0.986-1.135$ & 0.116 & & & \\
\hline DM & 4.182 & $2.373-7.370$ & $<0.001$ & 1.477 & $0.6 \mid 4-3.554$ & 0.384 \\
\hline CAD & 4.266 & $1.535-11.853$ & 0.005 & 1.456 & $0.418-5.073$ & 0.555 \\
\hline $\mathrm{CHF}$ & 0.671 & $0.163-2.758$ & 0.580 & & & \\
\hline Stroke & 3.120 & $1.407-6.923$ & 0.005 & 1.397 & $0.536-3.64 I$ & 0.494 \\
\hline SLE & 0.460 & $0.064-3.327$ & 0.442 & & & \\
\hline Liver cirrhosis & 1.885 & $0.749-4.744$ & 0.178 & & & \\
\hline Hepatitis B & 0.888 & $0.379-2.079$ & 0.784 & & & \\
\hline Hepatitis C & 1.627 & $0.647-4.093$ & 0.301 & & & \\
\hline PD duration (months) & 0.997 & $0.990-1.005$ & 0.494 & & & \\
\hline Residual urine & 0.544 & $0.313-0.945$ & 0.031 & 0.730 & $0.389-1.373$ & 0.329 \\
\hline White blood cell count $(1,000 / \mu \mathrm{L})$ & 1.054 & $0.963-1.154$ & 0.250 & & & \\
\hline Hemoglobin (g/dL) & 0.853 & $0.716-1.017$ & 0.077 & & & \\
\hline Platelet count $(1,000 / \mu \mathrm{L})$ & 0.998 & $0.995-1.002$ & 0.416 & & & \\
\hline Albumin (g/dL) & 0.397 & $0.227-0.691$ & 0.001 & 0.575 & $0.231-1.432$ & 0.235 \\
\hline Total cholesterol (mg/dL) & 0.998 & $0.993-1.004$ & 0.527 & & & \\
\hline HDL (mg/dL) & 0.991 & $0.97 I-1.012$ & 0.399 & & & \\
\hline LDL (mg/dL) & 0.996 & $0.988-1.003$ & 0.277 & & & \\
\hline Triglyceride (mg/dL) & $\mathrm{I} .00 \mathrm{I}$ & $0.999-1.003$ & 0.391 & & & \\
\hline HbAlc (\%) & 1.456 & I.209-I.753 & $<0.001$ & 1.028 & $0.694-1.523$ & 0.889 \\
\hline Blood urine nitrogen (mg/dL) & 0.998 & $0.983-1.014$ & 0.842 & & & \\
\hline Creatinine (mg/dL) & 0.905 & $0.820-0.999$ & 0.048 & 1.119 & $0.987-1.268$ & 0.080 \\
\hline Uric acid (mg/dL) & 1.085 & $0.874-1.346$ & 0.462 & & & \\
\hline Calcium (mg/dL) & 0.845 & $0.650-1.099$ & 0.208 & & & \\
\hline Phosphorus (mg/dL) & 0.906 & $0.732-1.120$ & 0.360 & & & \\
\hline Aluminum $(\mu g / d L)$ & 0.921 & $0.643-1.319$ & 0.653 & & & \\
\hline ¡PTH (pg/mL) & 1.000 & $0.999-1.000$ & 0.403 & & & \\
\hline
\end{tabular}


Table 4 (Continued)

\begin{tabular}{|c|c|c|c|c|c|c|}
\hline & \multicolumn{3}{|c|}{ Univariate } & \multicolumn{3}{|c|}{ Multivariate (enter method) } \\
\hline & HR & $95 \% \mathrm{Cl}$ & $P$-value & $\mathbf{H R}$ & $95 \% \mathrm{Cl}$ & $P$-value \\
\hline Transferrin saturation (\%) & 0.033 & $0.002-0.589$ & 0.020 & 0.083 & $0.004-1.948$ & 0.122 \\
\hline Ferritin $(\mu \mathrm{g} / \mathrm{L})$ & 1.000 & $1.000-1.001$ & 0.350 & & & \\
\hline PD system (Fresenius Stay Safe) & 0.902 & $0.125-6.529$ & 0.919 & & & \\
\hline PD modality (APD) & 1.439 & $0.754-2.743$ & 0.270 & & & \\
\hline Daily dwell volume (L) & 1.003 & $0.873-1.153$ & 0.961 & & & \\
\hline Icodextrin & 0.625 & $0.360-1.083$ & 0.094 & & & \\
\hline Nutrineal & 1.589 & $0.826-2.973$ & 0.323 & & & \\
\hline Dialysate dextrose (\%) & 1.235 & $0.724-2.104$ & 0.439 & & & \\
\hline Dialysate calcium (2.5 mEq/L) & 1.114 & $0.677-1.833$ & 0.671 & & & \\
\hline Dialysate/plasma creatinine & 13.239 & $1.386-126.46$ & 0.025 & 2.703 & $0.175-41.773$ & 0.477 \\
\hline Weekly Kt/V urea (total) & 0.442 & $0.200-1.003$ & 0.053 & & & \\
\hline Weekly CCr (normalized) & 0.977 & $0.956-1.012$ & 0.062 & & & \\
\hline Cardiovascular event(s) & 4.792 & $2.750-8.350$ & $<0.001$ & 2.092 & $1.086-4.028$ & 0.027 \\
\hline Infection episode(s) & 2.093 & $1.097-3.993$ & 0.025 & 1.110 & $0.558-2.206$ & 0.766 \\
\hline Malignancy & 1.610 & $0.758-3.421$ & 0.215 & & & \\
\hline EPS & 0.046 & $0.000-14.748$ & 0.296 & & & \\
\hline
\end{tabular}

Abbreviations: HR, hazard ratio; $\mathrm{Cl}$, confidence interval; HS-CRP, high-sensitivity C-reactive protein; DM, diabetes mellitus; CAD, coronary artery disease; CHF, congestive heart failure; SLE, systemic lupus erythematosus; PD, peritoneal dialysis; HDL, high-density lipoprotein; LDL, low-density lipoprotein; HbA I c, glycated hemoglobin; iPTH, intact parathyroid hormone; APD, automated peritoneal dialysis; CCr, creatinine clearance; EPS, encapsulating peritoneal sclerosis.

or CAD $(P=0.019)$, longer PD duration $(P<0.001)$, absence of residual urine $(P=0.007)$, lower hemoglobin levels $(P=0.009)$, lower serum albumin levels $(P=0.001)$, higher HbA1c levels $(P=0.040)$, higher serum aluminum levels $(P=0.044)$, higher mean dialysate dextrose level $(P=0.015)$, higher dialysate-to-plasma concentrations for creatinine $(P=0.003)$, and the occurrence of cardiovascular

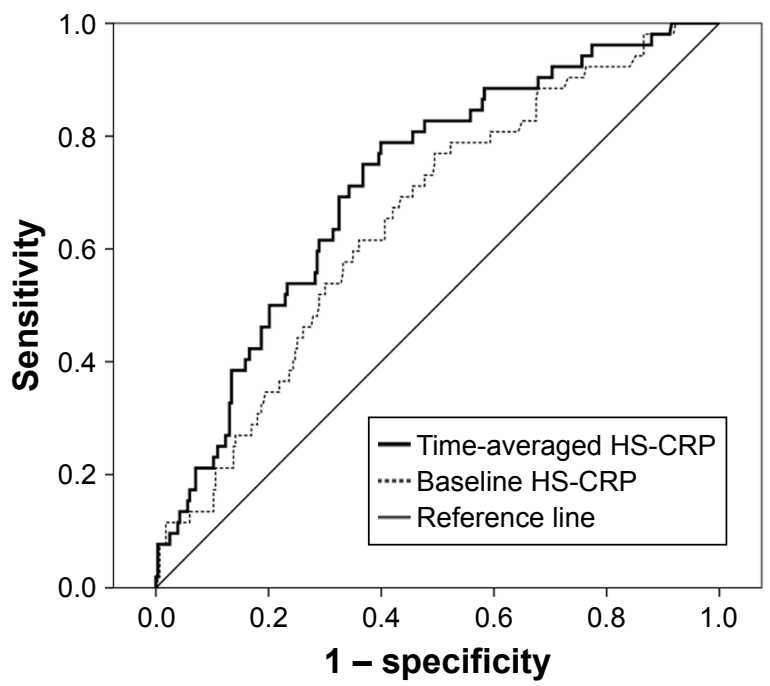

Figure 3 ROC curve analysis for predictability of mortality between the timeaveraged and baseline HS-CRP levels.

Notes: Results of the ROC curve analysis for predictability of mortality are shown. The mortality predictability of serum time-averaged HS-CRP levels appeared superior to serum baseline HS-CRP levels (AUCs: 0.717 compared with 0.653; $P=0.028)$.

Abbreviations: HS-CRP, high-sensitivity C-reactive protein; ROC, receiver operating characteristic; AUC, areas under ROC curve. event(s) $(P<0.001)$, infective episode(s) $(P<0.001)$, or EPS $(P<0.001)$ during the entire follow-up period were significant risk factors for dropout (Table 5). The multicollinearity of these variables was checked, and there was no variable with a VIF more than 5. The multivariate Cox regression analysis (enter method) revealed that a higher timeaveraged serum HS-CRP level $(P=0.015)$, the occurrence of cardiovascular event(s) $(P=0.043)$, infective episode(s) ( $P=0.003)$, or EPS $(P=0.013)$ during the entire follow-up period were independent predictors of dropout (Table 5). To compare dropout predictability of serum baseline and time-averaged HS-CRP levels, ROC curve analyses were conducted. As shown in Figure 4, the dropout predictability of serum time-averaged HS-CRP levels appeared superior to serum baseline HS-CRP levels (AUCs: 0.714 compared with $0.659 ; P=0.048)$.

\section{Discussion}

In this observational cohort study, 335 patients were enrolled to assess the risk factors associated with an elevated timeaveraged serum HS-CRP level (without active infection) and the impact of time-averaged serum HS-CRP level on mortality and dropout in patients on PD. This study demonstrated that 164 patients on PD (49.0\%) had elevated time-averaged serum HS-CRP levels $(>5 \mathrm{mg} / \mathrm{L})$, similar to the Turkish report (47.4\%). ${ }^{29}$ In this study, patients in the high time-averaged serum HS-CRP tertile had a higher mortality and dropout rate during the 60-month follow-up. 
Table 5 Hazard ratio of dropout (transplantation censored) in univariate and multivariate Cox regression analysis

\begin{tabular}{|c|c|c|c|c|c|c|}
\hline & \multicolumn{3}{|c|}{ Univariate } & \multicolumn{3}{|c|}{ Multivariate (enter method) } \\
\hline & HR & $95 \% \mathrm{Cl}$ & $P$-value & HR & $95 \% \mathrm{CI}$ & $P$-value \\
\hline Baseline serum HS-CRP (mg/L) & 1.008 & $1.001-1.017$ & 0.048 & 0.985 & $0.968-1.003$ & 0.106 \\
\hline Time-averaged serum HS-CRP (mg/L) & 1.024 & $1.015-1.034$ & $<0.001$ & 1.024 & $1.005-1.044$ & 0.015 \\
\hline Male & 1.060 & $0.756-1.487$ & 0.735 & & & \\
\hline Age (years) & 1.028 & $1.014-1.041$ & $<0.001$ & 1.012 & $0.995-1.029$ & 0.156 \\
\hline Body mass index $\left(\mathrm{kg} / \mathrm{m}^{2}\right)$ & 0.989 & $0.946-1.035$ & 0.642 & & & \\
\hline DM & 1.895 & $1.282-2.802$ & 0.001 & 1.189 & $0.635-2.224$ & 0.588 \\
\hline CAD & 2.478 & I.159-5.295 & 0.019 & 1.463 & $0.60 \mathrm{I}-3.564$ & 0.402 \\
\hline $\mathrm{CHF}$ & 1.202 & $0.633-2.282$ & 0.575 & & & \\
\hline Stroke & 1.703 & $0.944-3.073$ & 0.077 & & & \\
\hline SLE & 0.500 & $0.159-1.568$ & 0.235 & & & \\
\hline Liver cirrhosis & 1.535 & $0.85 I-2.77 \mid$ & 0.155 & & & \\
\hline Hepatitis B & 1.198 & $0.768-1.867$ & 0.425 & & & \\
\hline Hepatitis C & 1.411 & $0.799-2.492$ & 0.235 & & & \\
\hline PD duration (months) & 1.006 & $1.003-1.010$ & $<0.001$ & 1.000 & $0.994-1.006$ & 0.919 \\
\hline Residual urine & 0.639 & $0.46 \mathrm{I}-0.886$ & 0.007 & 0.997 & $0.613-1.621$ & 0.990 \\
\hline White blood cell count $(I, 000 / \mu \mathrm{L})$ & 1.032 & $0.977-1.091$ & 0.259 & & & \\
\hline Hemoglobin (g/dL) & 0.871 & $0.785-0.966$ & 0.009 & 0.958 & $0.84 I-I .092$ & 0.522 \\
\hline Platelet count $(I, 000 / \mu \mathrm{L})$ & 1.001 & $0.999-1.003$ & 0.351 & & & \\
\hline Albumin (g/dL) & 0.566 & $0.399-0.804$ & 0.001 & 0.651 & $0.377-1.125$ & 0.124 \\
\hline Total cholesterol (mg/dL) & 0.999 & $0.996-1.002$ & $0.44 I$ & & & \\
\hline Triglyceride (mg/dL) & 1.000 & $0.998-1.001$ & 0.907 & & & \\
\hline $\mathrm{HDL}(\mathrm{mg} / \mathrm{dL})$ & 1.000 & $0.988-1.012$ & 0.966 & & & \\
\hline LDL (mg/dL) & 0.998 & $0.994-1.003$ & 0.398 & & & \\
\hline $\mathrm{HbAIc}(\%)$ & 1.168 & $1.007-1.355$ & 0.040 & 0.966 & $0.754-1.238$ & 0.786 \\
\hline Blood urine nitrogen (mg/dL) & 0.992 & $0.982-1.001$ & 0.087 & & & \\
\hline Creatinine $(\mathrm{mg} / \mathrm{dL})$ & 0.950 & $0.898-1.004$ & 0.070 & & & \\
\hline Uric acid (mg/dL) & 0.920 & $0.806-1.052$ & 0.223 & & & \\
\hline Calcium (mg/dL) & 0.999 & $0.852-1.172$ & 0.994 & & & \\
\hline Phosphorus (mg/dL) & 0.915 & $0.809-1.035$ & 0.159 & & & \\
\hline Aluminum $(\mu \mathrm{g} / \mathrm{dL})$ & 1.183 & $1.005-1.394$ & 0.044 & 1.062 & $0.875-1.289$ & $0.54 I$ \\
\hline iPTH (pg/mL) & 1.000 & $0.999-1.000$ & 0.679 & & & \\
\hline Transferrin saturation (\%) & 0.458 & $0.113-1.863$ & 0.275 & & & \\
\hline Ferritin $(\mu g / L)$ & 1.000 & $1.000-1.000$ & 0.144 & & & \\
\hline PD system (Fresenius Stay Safe) & 0.580 & $0.144-2.341$ & 0.444 & & & \\
\hline PD modality (APD) & 1.297 & $0.878-1.916$ & 0.191 & & & \\
\hline Daily dwell volume (L) & 1.031 & $0.95 \mathrm{I}-1.118$ & 0.455 & & & \\
\hline Icodextrin & 0.762 & $0.554-1.047$ & 0.094 & & & \\
\hline Nutrineal & 1.364 & $0.863-2.562$ & 0.269 & & & \\
\hline Dialysate dextrose (\%) & 1.450 & $1.075-1.956$ & 0.015 & $1.25 \mathrm{I}$ & $0.825-1.899$ & 0.292 \\
\hline Dialysate calcium (2.5 mEq/L) & 0.953 & $0.708-1.282$ & 0.750 & & & \\
\hline Dialysate/plasma creatinine & 7.680 & $2.037-28.954$ & 0.003 & 0.883 & $0.125-6.218$ & 0.901 \\
\hline Weekly Kt/V urea (total) & 0.939 & $0.608-1.450$ & 0.775 & & & \\
\hline Weekly CCr (normalized) & 0.993 & $0.982-1.005$ & 0.235 & & & \\
\hline Cardiovascular event(s) & 1.853 & $1.331-2.579$ & $<0.001$ & 1.539 & $1.014-2.337$ & 0.043 \\
\hline Infective episode(s) & 2.843 & $1.874-4.312$ & $<0.001$ & 2.047 & $1.279-3.276$ & 0.003 \\
\hline Malignancy & 1.478 & $0.94 I-2.323$ & 0.090 & & & \\
\hline EPS & 2.519 & I.497-4.237 & $<0.001$ & 2.313 & $1.192-4.488$ & 0.013 \\
\hline
\end{tabular}

Abbreviations: HR, hazard ratio; $\mathrm{Cl}$, confidence interval; HS-CRP, high-sensitivity C-reactive protein; DM, diabetes mellitus; CAD, coronary artery disease; CHF, congestive heart failure; SLE, systemic lupus erythematosus; PD, peritoneal dialysis; HDL, high-density lipoprotein; LDL, low-density lipoprotein; HbA Ic, glycated hemoglobin; iPTH, intact parathyroid hormone; APD, automated peritoneal dialysis; $\mathrm{CCr}$, creatinine clearance; EPS, encapsulating peritoneal sclerosis.

Correspondingly, the multivariate Cox regression analysis also demonstrated that the time-averaged serum HS-CRP level is superior to a single baseline measurement as an independent predictor of mortality and dropout.
In this study, the proportion of DM and serum HbA1C levels were increased across the three tertiles. As patients with DM, especially those with poor blood glucose control, are a higher risk of inflammation compared with non-DM 


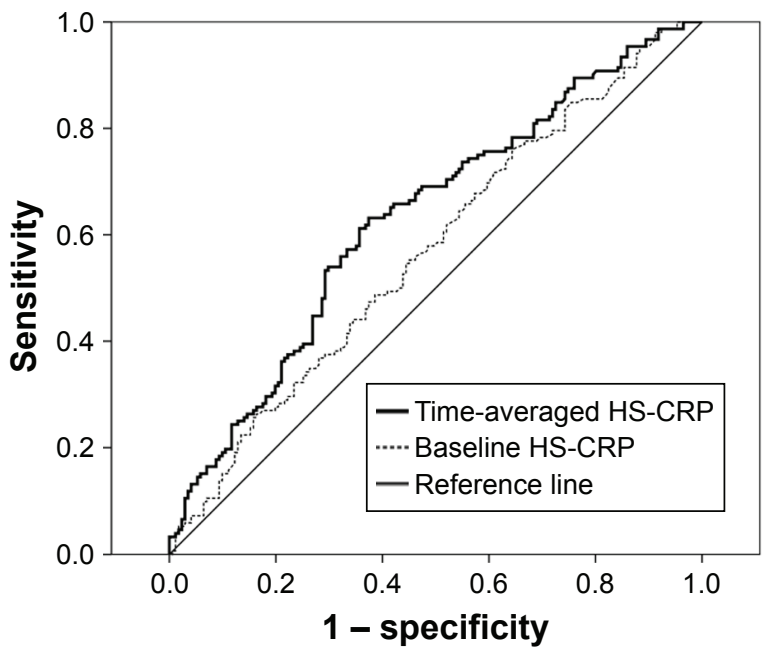

Figure 4 ROC curve analysis for predictability of dropout between the timeaveraged and baseline HS-CRP levels.

Notes: Results of the ROC curve analysis for predictability of dropout are shown. The dropout predictability of serum time-averaged HS-CRP levels appeared superior to serum baseline HS-CRP levels (AUCs: 0.714 compared with 0.659; $P=0.048$ ).

Abbreviations: HS-CRP, high-sensitivity $C$-reactive protein; ROC, receiver operating characteristic; AUC, areas under ROC curve.

patients $;{ }^{30}$ more patients with DM and higher HbA1C levels were found in the middle and upper HS-CRP tertiles in comparison to those in the lower tertile. The analysis of lipid profiles demonstrated elevated TG levels and reduced serum HDL cholesterol levels with increased time-average HS-CRP levels. As absorbed glucose contributes to increased TG levels in patients on $\mathrm{PD},{ }^{31}$ the increased proportion of patients with $\mathrm{DM}$, also reflected by an increase in $\mathrm{HbA1C}$ levels, across the three tertiles possibly caused higher serum TG levels in the upper tertile. High TG levels and low HDL cholesterol levels have been reported in patients on PD. ${ }^{32}$ HDL is a protector of vascular inflammation as suppression of cytokine secretion from macrophages and inhibition of LDL oxidation. ${ }^{33}$ This may explain lower HDL cholesterol levels in the middle and upper tertiles.

Ma et al reported that serum HS-CRP concentration in patients with chronic hepatitis B was significantly higher than in healthy controls. ${ }^{34}$ This study showed a significant increase in the number of patients with hepatitis B as the tertile increased. It was speculated that chronic hepatitis B infection may present a higher inflammation status and, thus, cause a higher HS-CRP level. However, the univariate Cox regression analysis demonstrated that the underlying hepatitis B was not a significant risk factor for mortality or PD dropout.

The relationship between serum HS-CRP and subsequent mortality in patients on PD remains inconclusive (Table 6). Although many studies have demonstrated that serum CRP is a powerful predictor of cardiovascular events and mortality, ${ }^{29,35-38}$ some studies have reported that serum CRP is not associated with all-cause mortality significantly. ${ }^{39,40}$ Moreover, membrane transporter status and residual urine have been reported as factors that affect serum CRP levels. ${ }^{41,42}$ Therefore, this literature controversy may be attributed to smaller sample sizes, different analyzed parameters, and shorter study periods.

Although the leading cause of mortality in patients on PD is cardiovascular complications, this study showed that infection - instead of cardiovascular complications - was the main culprit of patient deaths during follow-up. Mailloux et al reported that cardiac mortality was not as frequent as anticipated and occurred mainly in patients on dialysis for less than 4 years ${ }^{43}$ In this study, patients had long PD duration (mean 52.7 months) when enrolled and received even longer follow-up (60 months), possibly leading to the finding that infection - but not cardiovascular complications - was the main cause of mortality.

An elevated serum CRP level is related to future cardiovascular events in patients with stable or unstable angina pectoris as it is linked to the degree of vascular atherosclerosis in coronary and peripheral arteries. ${ }^{44,45}$ Cardiovascular events are the leading cause of mortality in the dialysis population; ${ }^{46,47}$ in addition to accelerated atherosclerosis, other factors include hypervolemic status and the presence of uremic toxins, anemia, hypoalbuminemia, vascular calcifications, and chronic inflammation. ${ }^{46,48,49}$ Serum CRP

Table 6 Comparison of the clinical outcomes between the current and published studies from different geographic areas

\begin{tabular}{|c|c|c|c|c|c|c|c|c|c|c|}
\hline Year & Country & $\begin{array}{l}\text { Sample } \\
\text { size }\end{array}$ & $\begin{array}{l}\text { Mean } \\
\text { age }\end{array}$ & DM & $\begin{array}{l}\text { Transfer } \\
\text { to HD }\end{array}$ & Mortality & $\begin{array}{l}\text { CRP } \\
\text { type }\end{array}$ & $\begin{array}{l}\text { Mean CRP } \\
(\mathrm{mg} / \mathrm{L})\end{array}$ & $\begin{array}{l}\text { Predictor of } \\
\text { dropout }\end{array}$ & $\begin{array}{l}\text { Predictor of } \\
\text { mortality }\end{array}$ \\
\hline $1998^{35}$ & Korea & 105 & 49.0 & $11.4 \%$ & $?$ & 2 -year $8.6 \%$ & CRP & 6.5 (baseline) & No (baseline) & Yes (baseline) \\
\hline $200 I^{39}$ & Australia & 50 & 63.0 & $20.0 \%$ & 3 -year $10.0 \%$ & 3 -year $56.0 \%$ & CRP & 8.0 (baseline) & - & No (baseline) \\
\hline $2003^{38}$ & Hong Kong & 246 & 55.0 & $30.9 \%$ & 2 -year $9.3 \%$ & 2 -year $24.0 \%$ & HS-CRP & 2.84 (baseline) & - & Yes (baseline) \\
\hline \multirow[t]{2}{*}{$2005^{29}$} & Turkey & 97 & 42.1 & $?$ & 3 -year $14.4 \%$ & 3 -year $18.6 \%$ & CRP & 7.2 (baseline) & - & No (baseline) \\
\hline & & & & & & & & 8.0 (averaged) & & Yes (averaged) \\
\hline $2010^{40}$ & Korea & 187 & 54.0 & $56.7 \%$ & 6-year $18.1 \%$ & 6 -year 31.6\% & HS-CRP & $?$ & No (baseline) & No (baseline) \\
\hline $2014^{22}$ & Taiwan & 402 & 48.6 & $17.7 \%$ & 2 -year $20.1 \%$ & 2 -year $7.0 \%$ & HS-CRP & 9.57 (baseline) & Yes (baseline) & Yes (baseline) \\
\hline
\end{tabular}

Abbreviations: DM, diabetes mellitus; HD, hemodialysis; CRP, C-reactive protein; HS-CRP, high-sensitivity C-reactive protein. 
level has been proved to be an independent risk factor of myocardial infarction and cardiovascular mortality in patients on PD. ${ }^{16,36,38,39}$ Although the incidence of cardiovascular event(s) was significantly increased across increasing timeaveraged serum HS-CRP tertiles, this study showed that time-averaged serum HS-CRP levels were still an independent predictor for all-cause mortality by multivariate Cox regression analysis.

In addition to mortality prediction, an elevated serum CRP level has been associated with PD dropout. However, seldom have studies evaluated the impact of serum CRP levels on PD dropout. The relationship between serum CRP levels and subsequent PD dropout remains unclear (summarized in Table 6). Zalunardo et al reported that the serum CRP was associated with short-term PD dropout independently, ${ }^{50}$ whereas the other two studies found that the serum CRP was not a risk factor for PD dropout. ${ }^{35,51}$ This study verified that the time-averaged serum HS-CRP level is well correlated with dropout in patients on PD.

The serum HS-CRP level reflects an inflammatory status, and the causes of elevated HS-CRP levels are, most of the time, difficult to identify. Several studies reported that a high proportion of dialysis patients $(30 \%-50 \%)$ had elevated serum CRP levels even if they did not have an active infectious status. ${ }^{38,39,52}$ Many factors have been proposed to cause an increase in serum CRP levels, including persistent occult infection, decreased renal clearance of pro-inflammatory cytokines, and increased oxidative stress in patients on dialysis. However, a direct correlation between these factors and elevated serum CRP levels has not been well identified. Regardless of interactions between these factors, serum CRP levels are commonly correlated with clinical outcome. Serum HS-CRP fluctuates throughout the PD course, implying that a single serum CRP measurement can underestimate or overestimate the predictive risk of mortality or dropout. In theory, a single serum CRP measurement may predict a short-term clinical outcome, but the averaged value of multiple HS-CRP measurements should outcompete the value of a single HS-CRP measurement in predicting the longer outcome. In fact, only 190 patients $(56.7 \%)$ had a stable HSCRP level in the present study, including 126 (37.6\%) who persistently had low levels ( $<5 \mathrm{mg} / \mathrm{L})$ and 64 (19.1\%) who persistently had high levels ( $>5 \mathrm{mg} / \mathrm{L})$. Up to 145 patients (43.3\%) had varied serum HS-CRP levels. A similar finding was also reported by Ateş et al, showing variation in CRP levels during regular follow-up. ${ }^{29}$ In the present study, the result of the multivariable Cox regression mode analysis revealed that the time-average serum HS-CRP level, instead of the baseline HS-CRP level, was an independent predictor of mortality and dropout in patients on PD. The ROC curve analysis also demonstrated that the mortality predictability of serum time-averaged HS-CRP level was superior to that of the serum baseline HS-CRP level. Therefore, the time-averaged serum HS-CRP level provides better value in predicting 5-year mortality and dropout in patients on PD as compared with a single HS-CRP level. These results suggest that repeated measurement at the regular bases is important for prediction of the long-term clinical outcome in patients on PD.

This study has some limitations. First, this study provides only a single-center experience and the analysis of multiple center data is required. Second, as this study excluded patients if they had only a single baseline measurement of HS-CRP, the selection bias would be inevitable. Third, patients with long PD duration are at a relatively higher risk of increased inflammation. Thus, those with relatively longer PD duration (mean 52.7 months) in this study had higher HS-CRP levels when compared to those patients with shorter PD duration in some studies. Clinical application of these results should be undertaken cautiously if the results are applied to patients having a short PD duration. Finally, as relatively younger (mean age 48.7 ) and more non-diabetic patients (84\%) preferred PD as the dialysis modality at Linkou Chang-Gung Hospital, application of these data to elder or diabetic patients on PD need to be further validated. However, large-scale and more comprehensive studies are required to overcome these limitations.

\section{Conclusion}

This study shows that the time-averaged serum HS-CRP level is superior to a single baseline HS-CRP measurement in predicting the 5-year mortality and dropout in patients on PD.

\section{Acknowledgment}

The authors thank all members of the Peritoneal Dialysis Unit, Linkou Chang Gung Memorial Hospital, for their invaluable help. This study was supported by grants from the Chung Gang Medical Research Project to Ya-Chung Tian and Yi-Jung Li (CORPG3F0191, CMRPG3A1201-1 3, CMRPG390921).

\section{Author contributions}

All authors contributed toward data analysis, drafting, and critical revision of the paper and agree to be accountable for all aspects of the work.

\section{Disclosure}

The authors report no conflicts of interest in this work. 


\section{References}

1. Pepys MB, Baltz ML. Acute phase proteins with special reference to C-reactive protein and related proteins (pentaxins) and serum amyloid A protein. Adv Immunol. 1983;34:141-212.

2. Zhang YX, Cliff WJ, Schoefl GI, Higgins G. Coronary C-reactive protein distribution: its relation to development of atherosclerosis. Atherosclerosis. 1999;145(2):375-379.

3. Kinoshita A, Onoda H, Imai N, Nishino H, Tajiri H. C-reactive protein as a prognostic marker in patients with hepatocellular carcinoma. Hepatogastroenterology. 2015;62(140):966-970.

4. Leuzzi G, Galeone C, Gisabella M, et al. Baseline C-reactive protein level predicts survival of early-stage lung cancer: evidence from a systematic review and meta-analysis. Tumori. 2016;102(5):441-449.

5. Volanakis JE, Narkates AJ. Interaction of C-reactive protein with artificial phosphatidylcholine bilayers and complement. J Immunol. 1981; 126(5):1820-1825.

6. Torzewski J, Torzewski M, Bowyer DE, et al. C-reactive protein frequently colocalizes with the terminal complement complex in the intima of early atherosclerotic lesions of human coronary arteries. Arterioscler Thromb Vasc Biol. 1998;18(9):1386-1392.

7. Lagrand WK, Visser CA, Hermens WT, et al. C-reactive protein as a cardiovascular risk factor: more than an epiphenomenon? Circulation. 1999;100(1):96-102.

8. Zacho J, Tybjaerg-Hansen A, Nordestgaard BG. C-reactive protein and all-cause mortality - the Copenhagen City Heart Study. Eur Heart J. 2010;31(13):1624-1632.

9. Festa A, D’Agostino R Jr, Howard G, Mykkänen L, Tracy RP, Haffner SM. Chronic subclinical inflammation as part of the insulin resistance syndrome: the Insulin Resistance Atherosclerosis Study (IRAS). Circulation. 2000;102(1):42-47.

10. Panichi V, Migliori M, De Pietro S, et al. C-reactive protein as a marker of chronic inflammation in uremic patients. Blood Purif. 2000; 18(3):183-190.

11. Meuwese CL, Stenvinkel P, Dekker FW, Carrero JJ. Monitoring of inflammation in patients on dialysis: forewarned is forearmed. Nat Rev Nephrol. 2011;7(3):166-176.

12. Filiopoulos V, Vlassopoulos D. Inflammatory syndrome in chronic kidney disease: pathogenesis and influence on outcomes. Inflamm Allergy Drug Targets. 2009;8(5):369-382.

13. Wanner C, Drechsler C, Krane V. C-reactive protein and uremia. Semin Dial. 2009;22(4):438-441.

14. Choi HY, Lee JE, Han SH, et al. Association of inflammation and protein-energy wasting with endothelial dysfunction in peritoneal dialysis patients. Nephrol Dial Transplant. 2010;25(4):1266-1271.

15. Honda H, Qureshi AR, Heimbürger O, et al. Serum albumin, C-reactive protein, interleukin 6 , and fetuin a as predictors of malnutrition, cardiovascular disease, and mortality in patients with ESRD. Am J Kidney Dis. 2006;47(1):139-148.

16. Wang AY, Lam CW, Chan IH, Wang M, Lui SF, Sanderson JE. Longterm mortality and cardiovascular risk stratification of peritoneal dialysis patients using a combination of inflammation and calcification markers. Nephrol Dial Transplant. 2009;24(12):3826-3833.

17. Filiopoulos V, Hadjiyannakos D, Takouli L, Metaxaki P, Sideris V, Vlassopoulos D. Inflammation and oxidative stress in end-stage renal disease patients treated with hemodialysis or peritoneal dialysis. Int $J$ Artif Organs. 2009;32(12):872-882.

18. Stenvinkel P, Ketteler M, Johnson RJ, et al. IL-10, IL-6, and TNF-alpha: central factors in the altered cytokine network of uremia - the good, the bad, and the ugly. Kidney Int. 2005;67(4):1216-1233.

19. Tarakçioğlu M, Erbağci AB, Usalan C, Deveci R, Kocabaş R. Acute effect of hemodialysis on serum levels of the proinflammatory cytokines. Mediators Inflamm. 2003;12(1):15-19.

20. London GM. Cardiovascular calcifications in uremic patients: clinical impact on cardiovascular function. J Am Soc Nephrol. 2003;14(9 Suppl4): S305-S309.
21. Yeun JY, Levine RA, Mantadilok V, Kaysen GA. C-Reactive protein predicts all-cause and cardiovascular mortality in hemodialysis patients. Am J Kidney Dis. 2000;35(3):469-476.

22. Liu SH, Li YJ, Wu HH, et al. High-sensitivity C-reactive protein predicts mortality and technique failure in peritoneal dialysis patients. PLoS One. 2014;9(3):e93063.

23. Wang AY, Brimble KS, Brunier G, et al. ISPD cardiovascular and metabolic guidelines in adult peritoneal dialysis patients part I-assessment and management of various cardiovascular risk factors. Perit Dial Int. 2015;35(4):379-387.

24. Kaysen GA, Dubin JA, Müller HG, Rosales LM, Levin NW. The acute-phase response varies with time and predicts serum albumin levels in hemodialysis patients. The HEMO Study Group. Kidney Int. 2000;58(1):346-352.

25. Nascimento MM, Pecoits-Filho R, Qureshi AR, et al. The prognostic impact of fluctuating levels of C-reactive protein in Brazilian haemodialysis patients: a prospective study. Nephrol Dial Transplant. 2004; 19(11):2803-2809.

26. den Elzen WP, van Manen JG, Boeschoten EW, Krediet RT, Dekker FW. The effect of single and repeatedly high concentrations of C-reactive protein on cardiovascular and non-cardiovascular mortality in patients starting with dialysis. Nephrol Dial Transplant. 2006;21(6):1588-1595.

27. Shemin D, Bostom AG, Laliberty P, Dworkin LD. Residual renal function and mortality risk in hemodialysis patients. Am J Kidney Dis. 2001;38(1):85-90.

28. Twardowski ZJ. Clinical value of standardized equilibration tests in CAPD patients. Blood Purif. 1989;7(2-3):95-108.

29. Ateş K, Ateş A, Ekmekçi Y, Nergizoglu G. The time course of serum C-reactive protein is more predictive of mortality than its baseline level in peritoneal dialysis patients. Perit Dial Int. 2005;25(3):256-268.

30. Shanmugam N, Reddy MA, Guha M, Natarajan R. High glucoseinduced expression of proinflammatory cytokine and chemokine genes in monocytic cells. Diabetes. 2003;52(5):1256-1264.

31. Lindholm B, Norbeck HE. Serum lipids and lipoproteins during continuous ambulatory peritoneal dialysis. Acta Med Scand. 1986;220(2): 143-151.

32. Holzer M, Schilcher G, Curcic S, et al. Dialysis modalities and HDL composition and function. J Am Soc Nephrol. 2015;26(9):2267-2276.

33. Aviram M, Rosenblat M, Bisgaier CL, Newton RS, Primo-Parmo SL, La Du BN. Paraoxonase inhibits high-density lipoprotein oxidation and preserves its functions. A possible peroxidative role for paraoxonase. J Clin Invest. 1998;101(8):1581-1590.

34. Ma LN, Liu XY, Luo X, et al. Serum high-sensitivity C-reactive protein are associated with HBV replication, liver damage and fibrosis in patients with chronic hepatitis B. Hepatogastroenterology. 2015;62(138): 368-372.

35. Noh H, Lee SW, Kang SW, et al. Serum C-reactive protein: a predictor of mortality in continuous ambulatory peritoneal dialysis patients. Perit Dial Int. 1998;18(4):387-394.

36. Ducloux D, Bresson-Vautrin C, Kribs M, Abdelfatah A, Chalopin JM. C-reactive protein and cardiovascular disease in peritoneal dialysis patients. Kidney Int. 2002;62(4):1417-1422.

37. Avram MM, Fein PA, Paluch MM, Schloth T, Chattopadhyay J. Association between $\mathrm{C}$-reactive protein and clinical outcomes in peritoneal dialysis patients. Adv Perit Dial. 2005;21:154-158.

38. Wang AY, Woo J, Lam CW, et al. Is a single time point C-reactive protein predictive of outcome in peritoneal dialysis patients? J Am Soc Nephrol. 2003;14(7):1871-1879.

39. Herzig KA, Purdie DM, Chang W, et al. Is C-reactive protein a useful predictor of outcome in peritoneal dialysis patients? J Am Soc Nephrol. 2001;12(4):814-821.

40. Cho JH, Hur IK, Kim CD, et al. Impact of systemic and local peritoneal inflammation on peritoneal solute transport rate in new peritoneal dialysis patients: a 1-year prospective study. Nephrol Dial Transplant. 2010;25(6):1964-1973. 
41. Pérez-Flores I, Coronel F, Cigarrán S, Herrero JA, Calvo N. Relationship between residual renal function, inflammation, and anemia in peritoneal dialysis. Adv Perit Dial. 2007;23:140-143.

42. Chung SH, Heimbürger O, Stenvinkel P, Bergström J, Lindholm B. Association between inflammation and changes in residual renal function and peritoneal transport rate during the first year of dialysis. Nephrol Dial Transplant. 2001;16(11):2240-2245.

43. Mailloux LU, Bellucci AG, Wilkes BM, et al. Mortality in dialysis patients: analysis of the causes of death. Am J Kidney Dis. 1991;18(3): 326-335.

44. Haverkate F, Thompson SG, Pyke SD, Gallimore JR, Pepys MB. Production of C-reactive protein and risk of coronary events in stable and unstable angina. European Concerted Action on Thrombosis and Disabilities Angina Pectoris Study Group. Lancet. 1997;349(9050): 462-466.

45. Heinrich J, Schulte H, Schönfeld R, Köhler E, Assmann G. Association of variables of coagulation, fibrinolysis and acute-phase with atherosclerosis in coronary and peripheral arteries and those arteries supplying the brain. Thromb Haemost. 1995;73(3):374-379.
46. Krediet RT, Balafa O. Cardiovascular risk in the peritoneal dialysis patient. Nat Rev Nephrol. 2010;6(8):451-460.

47. Li PK, Chow KM. The clinical and epidemiological aspects of vascular mortality in chronic peritoneal dialysis patients. Perit Dial Int. 2005; 25 Suppl 3:S80-S83.

48. Johnson DW, Craven AM, Isbel NM. Modification of cardiovascular risk in hemodialysis patients: an evidence-based review. Hemodial Int. 2007;11(1):1-14.

49. Nolan CR. Strategies for improving long-term survival in patients with ESRD. J Am Soc Nephrol. 2005;16 Suppl 2:S120-S127.

50. Zalunardo NY, Rose CL, Ma IW, Altmann P. Higher serum C-reactive protein predicts short and long-term outcomes in peritoneal dialysisassociated peritonitis. Kidney Int. 2007;71(7):687-692.

51. Westhuyzen J, Mills K, Healy H. Predicting clinical outcomes in peritoneal dialysis patients using small solute modeling. Ann Clin Lab Sci. 2005;35(1):46-53.

52. Yeun JY, Kaysen GA. Acute phase proteins and peritoneal dialysate albumin loss are the main determinants of serum albumin in peritoneal dialysis patients. Am J Kidney Dis. 1997;30(6):923-927.
Therapeutics and Clinical Risk Management

\section{Publish your work in this journal}

Therapeutics and Clinical Risk Management is an international, peerreviewed journal of clinical therapeutics and risk management, focusing on concise rapid reporting of clinical studies in all therapeutic areas outcomes, safety, and programs for the effective, safe, and sustained use of medicines. This journal is indexed on PubMed Central, CAS,

\section{Dovepress}

EMBase, Scopus and the Elsevier Bibliographic databases. The manuscript management system is completely online and includes a very quick and fair peer-review system, which is all easy to use. Visit http://www.dovepress.com/testimonials.php to read real quotes from published authors.

Submit your manuscript here: http://www.dovepress.com/therapeutics-and-clinical-risk-management-journal 